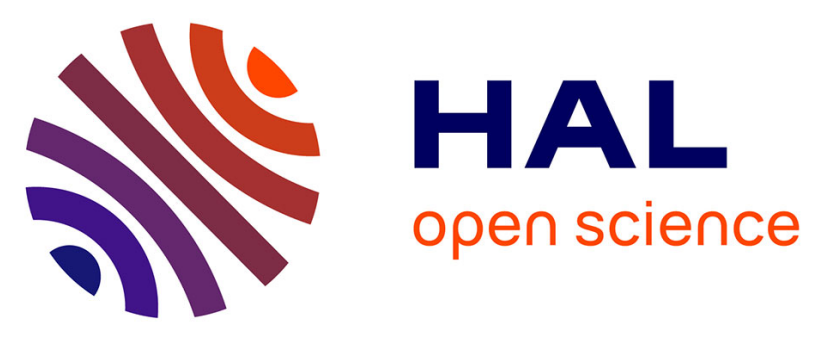

\title{
Gamma irradiation effects on morphology and properties of PHBV/PLA blends in presence of compatibilizer and Cloisite 30B
}

Idris Zembouai, Mustapha Kaci, Stephane Bruzaud, Loic Dumazert, Alain Bourmaud, Mohamed Mahlous, Jose Marie Lopez-Cuesta, Yves Grohens

\section{To cite this version:}

Idris Zembouai, Mustapha Kaci, Stephane Bruzaud, Loic Dumazert, Alain Bourmaud, et al.. Gamma irradiation effects on morphology and properties of PHBV/PLA blends in presence of compatibilizer and Cloisite 30B. Polymer Testing, 2016, 49, pp.29-37. 10.1016/j.polymertesting.2015.11.003 . hal02906422

\section{HAL Id: hal-02906422 \\ https://hal.science/hal-02906422}

Submitted on 26 May 2021

HAL is a multi-disciplinary open access archive for the deposit and dissemination of scientific research documents, whether they are published or not. The documents may come from teaching and research institutions in France or abroad, or from public or private research centers.
L'archive ouverte pluridisciplinaire HAL, est destinée au dépôt et à la diffusion de documents scientifiques de niveau recherche, publiés ou non, émanant des établissements d'enseignement et de recherche français ou étrangers, des laboratoires publics ou privés. 


\title{
Gamma irradiation effects on morphology and properties of PHBV/PLA blends in presence of compatibilizer and Cloisite 30B
}

\author{
Idris Zembouai a , Mustapha Kaci a , Stéphane Bruzaud ${ }^{\text {b, * }}$, Loic Dumazert ${ }^{\text {, }}$, \\ Alain Bourmaud ${ }^{\mathrm{b}}$, Mohamed Mahlous ${ }^{\mathrm{d}}$, José Marie Lopez-Cuesta ${ }^{\mathrm{c}}$, Yves Grohens ${ }^{\mathrm{b}}$ \\ a Laboratoire des Matériaux Polymères Avancés (LMPA), Faculté de Technologie, Université de Bejaia, 06000, Algeria \\ ${ }^{\mathrm{b}}$ Laboratoire d'Ingénierie des Matériaux de Bretagne (LIMATB), Université de Bretagne-Sud, Rue de Saint Maudé, 56321 Lorient Cedex, France \\ ${ }^{\mathrm{c}}$ Centre des Matériaux des Mines d'Alès (C2MA), Ecole des Mines d'Alès, 6 avenue de Clavières, 30319 Alès Cedex, France \\ ${ }^{\mathrm{d}}$ Centre de Recherche Nucléaire d'Alger (CRNA), 2 Boulevard Frantz Fanon, Alger 16000, Algeria
}

\section{A B S T R A C T}

The effects of gamma irradiation on the morphology and physical properties of various blends based on poly(3-hydroxybutyrate-co-3-hydroxyvalerate) (PHBV) and polylactide (PLA): 50/50 w/w were studied with and without PHBV-g-MA and organomodified montmorillonite used as the compatibilizer and reinforcement agent, respectively. The different blend compositions prepared by melt compounding were compression molded to thin films of an average thickness of $150 \mu \mathrm{m}$, and subjected to 25,50 and $100 \mathrm{kGy}$ at room temperature; the dose rate being $1.0 \mathrm{~Gy} / \mathrm{h}$. Infrared spectra analysis indicated the occurrence of some chemical modifications in the irradiated samples, in particular an absorbed dose of $100 \mathrm{kGy}$ resulted in the formation of a large absorption band in the carbonyl region. Size exclusion chromatography (SEC) data showed a decrease in the average molecular weight for all irradiated samples with increasing absorbed dose due to chain scission. Nanoindentation tests showed that $\gamma$-irradiation significantly decreased both modulus and hardness of neat PHBV and neat PLA after $100 \mathrm{kGy}$, whereas no noticeable changes were observed for PHBV/PLA blends. Thermogravimetric analysis (TGA) and pyrolysis combustion flow calorimetry (PCFC) tests revealed that the organomodified clay can act as a compatibilizer and compensate for the effect of irradiation on both thermal stability and fire retardancy of PHBV/ PLA blends.

\section{Keywords:}

PHBV

PLA

Polymer blends

Gamma radiation

Morphology

Relationship structure/properties

\section{Introduction}

Plastics packaging is one of the biggest sectors of the polymer processing industry, with the food sector being its principal customer [1]. However, most synthetic polymers used for this application often have short service life, so they end up mostly in landfills. The non-biodegradability of such commercial plastics has caused many environmental problems associated with their disposal [2,3]. Due to their biodegradability and biocompatibility through non toxic intermediates, PHBV and PLA are considered as ideal candidates to replace non biodegradable polymeric materials for packaging applications [4]. Further, they can be processed in equipment commonly used for synthetic polymers. On the other hand, there has been significant interest in the gamma sterilization

\footnotetext{
* Corresponding author.

E-mail address: stephane.bruzaud@univ-ubs.fr (S. Bruzaud).
}

of polymers being used in some technological fields such as biomedical and food packaging to guarantee microbiological safety $[5,6]$. However, it is known that $\gamma$-irradiation may cause some undesirable effects on polymers [7]. Therefore, it becomes necessary to study the chemical and physical effects that are induced by the transfer of energy to the polymer [8]. Often, the occurrence of these effects makes the irradiated materials unsuitable for some applications. Indeed, several papers [9-12] reported that $\gamma$-irradiation of polymers generally produces simultaneous scission and crosslinking of the polymeric chains. The latter causes the formation of a macroscopic network, which reduces gas permeability and improves mechanical properties, whereas the former decreases mechanical properties, but increases the biodegradation rate. In this respect, considerable work has been published on oxidative degradation of PHBV or PLA under gamma irradiation at both higher and lower doses [13-18]. One of the significant conclusions that can be drawn from these publications is, in particular, the decrease in molecular weight of the irradiated polymers below 
$100 \mathrm{kGy}$ due to chain scission, which occurs in the amorphous region and continues further to crystalline regions at higher doses. Melting point $\left(T_{m}\right)$ and glass transition temperature $\left(T_{g}\right)$ are reduced with increasing radiation dose, while the degree of crystallinity increases. The values of the surface potential of the irradiated biopolymers were higher in comparison with the nonirradiated samples. However, to the best of our knowledge, literature data dealing with $\gamma$-irradiation effects on polymer blends, in particular those based on PHBV/PLA, are rather scarce.

In this work, which is a continuation of previous ones devoted to the characterization properties of PHBV/PLA blends, and the methods for improving their compatibility and recycling [19-22], the assigned objective was to study the effects of $\gamma$-irradiation up to $100 \mathrm{kGy}$ on the chemical structure, morphology and physical properties of blends based on PHBV/PLA: 50/50 w/w. Furthermore, the changes induced by $\gamma$-irradiation on the morphology and properties of PHBV/PLA blends were evaluated in the presence of 5 wt.\% of PHBV-g-MA and 3 wt.\% of Cloisite 30B used as compatibilizer and filler, respectively.

\section{Experimental part}

\subsection{Materials used}

PLA was supplied in pellets form by NatureWorks under the trade name 7001D. The polymer is semi crystalline having the following properties: density $=1.25 \mathrm{~g} / \mathrm{cm}^{3}$, MFI $=6 \mathrm{~g} / 10 \mathrm{~min}$ $\left(210{ }^{\circ} \mathrm{C}, 2.16 \mathrm{~kg}\right), \mathrm{T}_{\mathrm{g}}=60^{\circ} \mathrm{C}$ and $\mathrm{T}_{\mathrm{m}}=160{ }^{\circ} \mathrm{C}$.

PHBV was manufactured by Tianan Biological Materials Co. Ltd. (China) and commercialized in pellets form under the trade name ENMAT Y1000P. According to the manufacturer, PHBV has the following properties: density $=1.25 \mathrm{~g} / \mathrm{cm}^{3}, \mathrm{~T}_{\mathrm{g}}=8{ }^{\circ} \mathrm{C}$ and $\mathrm{T}_{\mathrm{m}}=165^{\circ} \mathrm{C}$. This grade has been comprehensively characterized in a recent paper [23].

Cloisite 30B (C30B) is an organically modified montmorillonite, which is commercially available and supplied by Southern Clay Products (Texas). C30B is a montmorillonite modified with bis-(2hydroxyethyl)methyl tallow alkyl ammonium cations. C30B was dried under vacuum at $60{ }^{\circ} \mathrm{C}$ for at least $24 \mathrm{~h}$ before any use.

Maleic anhydride (MA) and dicumyl peroxide (DCP) were obtained from Sigma-Aldrich and used as received.

PHBV-g-MA was prepared by reactive extrusion in the laboratory according to the process previously described in the literature [21]. The MA content was 0.29 wt.\%.

\subsection{Sample preparation}

Prior to use, all materials were dried under vacuum at $60{ }^{\circ} \mathrm{C}$ for $24 \mathrm{~h}$. Drying was necessary in order to minimize the hydrolytic degradation of the polymers during melt processing. The samples of various blend compositions shown in Table 1 were prepared in an internal mixer according to the procedure previously described [21]. The mixing temperature, screw speed and residence time were set at $180{ }^{\circ} \mathrm{C}, 50 \mathrm{rpm}$ and $8 \mathrm{~min}$, respectively. The resulting materials were ground into pellets. Prior to compression molding, the pellets were dried under vacuum at $60{ }^{\circ} \mathrm{C}$ and compression molded in a Carver ${ }^{\circledR}$ hydraulic press at $180^{\circ} \mathrm{C}$ under a pressure of 10 metric tons for $3 \mathrm{~min}$ to obtain films of about $150 \mu \mathrm{m}$ of thickness.

\subsection{Gamma irradiation test}

Gamma irradiation was carried out on circular film samples of almost $20 \mathrm{~cm}$ diameter, placed in the ${ }^{60} \mathrm{Co}$ pilot irradiator at the Nuclear Research Center of Algiers (CRNA), Algeria. The samples were exposed to 25,50 and $100 \mathrm{kGy}$ at a dose rate of $1 \mathrm{~Gy} \mathrm{~h}^{-1}$ in the presence of air at room temperature.

\subsection{Technical characterization}

\subsubsection{Fourier transform infrared spectroscopy (FT-IR)}

FT-IR spectra of various film samples were recorded by an FT-IR spectrometer (Shimadzu $8400 \mathrm{M}$ ) using $4 \mathrm{~cm}^{-1}$ resolution and 40 scans. All spectra were recorded in the absorbance mode in the $4000-400 \mathrm{~cm}^{-1}$ region.

\subsubsection{Molecular weight measurements by SEC}

Size exclusion chromatography (SEC) was used to determine the evolution of molecular weight. The apparatus was equipped with a set of three columns: two ResiPore and one PLgel Mixed C (Polymer Labs.). The detection system was composed by a refractometer and a UV detector. Chloroform was used as an eluant with a flow rate of $0.8 \mathrm{~mL} / \mathrm{min}$. The elution profiles were analyzed by the Empower SEC module software (Waters). Calculations were based on calibration curves obtained from polystyrene standards ranging from $200 \mathrm{~g} / \mathrm{mol}$ up to $6 \times 10^{6}$. The weight-average molecular weight $\bar{M}_{w}$ and number-average molecular weight $\bar{M}_{n}$ were obtained from the SEC analysis. The polydispersity index (PDI) was calculated as the ratio of $\bar{M}_{w} / \bar{M}_{n}$.

\subsubsection{Differential scanning calorimetry (DSC)}

DSC analyzes were performed on weighted samples of about $10 \mathrm{mg}$, using a Mettler-Toledo DSC-882 equipment. The samples were subjected to two heating and cooling ramps starting from $-40{ }^{\circ} \mathrm{C}$ up to $+200{ }^{\circ} \mathrm{C}$ and down to $-40{ }^{\circ} \mathrm{C}$ with a scanning rate of $10^{\circ} \mathrm{C} \mathrm{min}^{-1}$ under nitrogen atmosphere. In the first run, the samples were heated from -40 to $+200{ }^{\circ} \mathrm{C}$ at a rate of $10{ }^{\circ} \mathrm{C} / \mathrm{min}$. After keeping the temperature at $200{ }^{\circ} \mathrm{C}$ for $2 \mathrm{~min}$, the samples were rapidly quenched to $-40{ }^{\circ} \mathrm{C}$. In the second run, they were heated at a rate of $10^{\circ} \mathrm{C} / \mathrm{min}$ to $+200{ }^{\circ} \mathrm{C}$. From DSC thermograms, thermal characteristics, i.e. crystallization temperature $\left(\mathrm{T}_{\mathrm{c}}\right)$, cold crystallization temperature $\left(\mathrm{T}_{\mathrm{cc}}\right)$, crystallization enthalpy $\left(\Delta \mathrm{H}_{\mathrm{c}}\right)$, cold crystallization enthalpy $\left(\Delta \mathrm{H}_{\mathrm{cc}}\right)$, melting temperature $\left(\mathrm{T}_{\mathrm{m}}\right)$ and melting enthalpy $\left(\Delta \mathrm{H}_{\mathrm{m}}\right)$ were determined.

\subsubsection{Thermogravimetric analysis (TGA)}

TGA experiments were carried out in a thermal analyzer (Setaram TG/DTA 92-10) using a heating rate of $10{ }^{\circ} \mathrm{C} \mathrm{min}{ }^{-1}$ under nitrogen atmosphere, between 20 and $600{ }^{\circ} \mathrm{C}$. The average sample mass was almost $10 \mathrm{mg}$.

\subsubsection{Nanoindentation test}

Nanoindentation testing involves the contact of an indenter on a material surface and its penetration into it to a specified load or depth. In this study, a flattened conical indenter was used. This geometry is well suitable to nanocomposites due to the high contact surface, generally inducing results with a low spread. Both the nanoindentation principle and method used to determine hardness and elastic modulus were described in previous work [24].

\subsubsection{Scanning electron microscopy (SEM)}

Morphological changes were observed using a Jeol JSM-6031 scanning electron microscope (SEM) to examine the fracture surface of the film samples. The neck region for the broken specimens fractured in liquid nitrogen is parallel to the draw direction in order to reveal the internal morphology. Prior to observation, the fracture surface was coated with a thin gold layer by means of a polaron sputtering apparatus.

\subsubsection{Pyrolysis combustion flow calorimeter (PCFC)}

Pyrolysis combustion flow calorimeter apparatus from FTT (UK) 
Table 1

Molecular weight changes as a function of absorbed doses for neat PHBV, neat PLA and various PHBV/PLA blends determined by SEC analysis.

\begin{tabular}{|c|c|c|c|c|}
\hline Samples & Absorbed dose (kGy) & $\bar{M}_{w}\left(\mathrm{~g} \mathrm{~mol}^{-1}\right)$ & $\bar{M}_{n}\left(\mathrm{~g} \mathrm{~mol}^{-1}\right)$ & $\bar{M}_{w} / \bar{M}_{n}$ \\
\hline \multirow[t]{3}{*}{ PHBV } & 0 & 231,500 & 153,600 & 1.60 \\
\hline & 50 & 102,900 & 65,100 & 1.57 \\
\hline & 100 & 62,300 & 40,000 & 1.55 \\
\hline \multirow[t]{3}{*}{ PLA } & 0 & 174,500 & 105900 & 1.64 \\
\hline & 50 & 66,500 & 49,800 & 1.33 \\
\hline & 100 & 39,300 & 29,800 & 1.32 \\
\hline \multirow[t]{3}{*}{ PHBV/PLA (50/50) } & 0 & 188,600 & 128,700 & 1.46 \\
\hline & 50 & 72,700 & 50,800 & 1.43 \\
\hline & 100 & 39,900 & 26,500 & 1.50 \\
\hline \multirow[t]{3}{*}{ PHBV/PLA/C30B (50/50/3) } & 0 & 176,200 & 123,500 & 1.20 \\
\hline & 50 & 68,300 & 46,700 & 1.46 \\
\hline & 100 & 42,100 & 30,000 & 1.40 \\
\hline \multirow[t]{3}{*}{ PHBV/PLA/C30B/PHBV-g-MA (50/50/3/5) } & 0 & 102,300 & 74,100 & 1.38 \\
\hline & 50 & 75,200 & 51,500 & 1.46 \\
\hline & 100 & 54,700 & 36,500 & 1.49 \\
\hline
\end{tabular}

was used to pyrolyze $3 \pm 1 \mathrm{mg}$ of sample by heating up to $900{ }^{\circ} \mathrm{C}$ at a rate of $1{ }^{\circ} \mathrm{C} \mathrm{s}^{-1}$ under a nitrogen flow. The gases released during pyrolysis were sent into a combustor and burnt at a temperature of $900{ }^{\circ} \mathrm{C}$ in the presence of oxygen (20\%). Peak heat release rate (PHRR) and heat release rate (HRR) of samples were noted and each measurement was performed at least five times (up to ten times). The results were averaged with an error of less than $5 \%$, while the error on temperature of PHRR ( $\left.T_{P H R R}\right)$ measurement is less than $1 \%$. The gases produced at temperature of PHRR observed during the PCFC test were analyzed.

\section{Results and discussion}

\subsection{FT-IR spectra analysis}

The material usefulness depends on its durability in the environment in which it is used, and also its interactions with environmental factors. The changes in the chemical structure induced by $\gamma$-irradiation exposure of neat polymers and PHBV/PLA blend $(50 / 50 \mathrm{w} / \mathrm{w})$ in the absence and presence of C30B and PHBV-g-MA were analyzed by FT-IR spectroscopy. Representative FT-IR spectra of non-irradiated and irradiated PHBV/PLA/C30B samples with the compatibilizer after absorbed dose of 25 and $100 \mathrm{kGy}$, and recorded in the hydroperoxide and carbonyl regions are shown in Fig. $1 \mathrm{a}$ and b, respectively. From Figs. 1(a), 2(a), 3(a) and 4(a), FT-IR spectrum of the non-irradiated sample exhibits large absorption bands centered at 3503 and $3438 \mathrm{~cm}^{-1}$, which correspond to the hydroperoxide groups probably resulting from the thermal degradation of the polymer blends during melt processing. After $\gamma$-irradiation exposure, the bands become stronger in intensity as the absorbed doses increase. In the region $1900-1500 \mathrm{~cm}^{-1}$ shown in Fig. 1(b) 2(b), 3 (b) and 4(b), which is relative to the carbonyl region, significant changes in the chemical structure have occurred in irradiated samples, especially at $100 \mathrm{kGy}$. Indeed, at this absorbed dose, the disappearance of the main absorption bands localized at 1779 and $1708 \mathrm{~cm}^{-1}$ characteristic of the neat polymers is observed. The formation of a large absorption band involving various carbonyl products, derived from samples irradiated up to $100 \mathrm{kGy}$ is seen at 1779,1746 and $1698 \mathrm{~cm}^{-1}$, which correspond to peresters, esters and carboxylic groups, respectively. This indicates that $\gamma$-irradiation of the compatibilized PHBV/PLA/C30B leads to oxidation reactions of ester groups resulting in the formation of hydroxyl groups contained in hydroperoxides, carboxylic acids and alcohols [25]. The amount of each species depends on the radiation dose, especially for the concentration of carboxylic groups, which are predominant when the dose is equal to $100 \mathrm{kGy}$. Similar conclusions can be deduced for with neat polymers, i.e. PHBV and PLA.
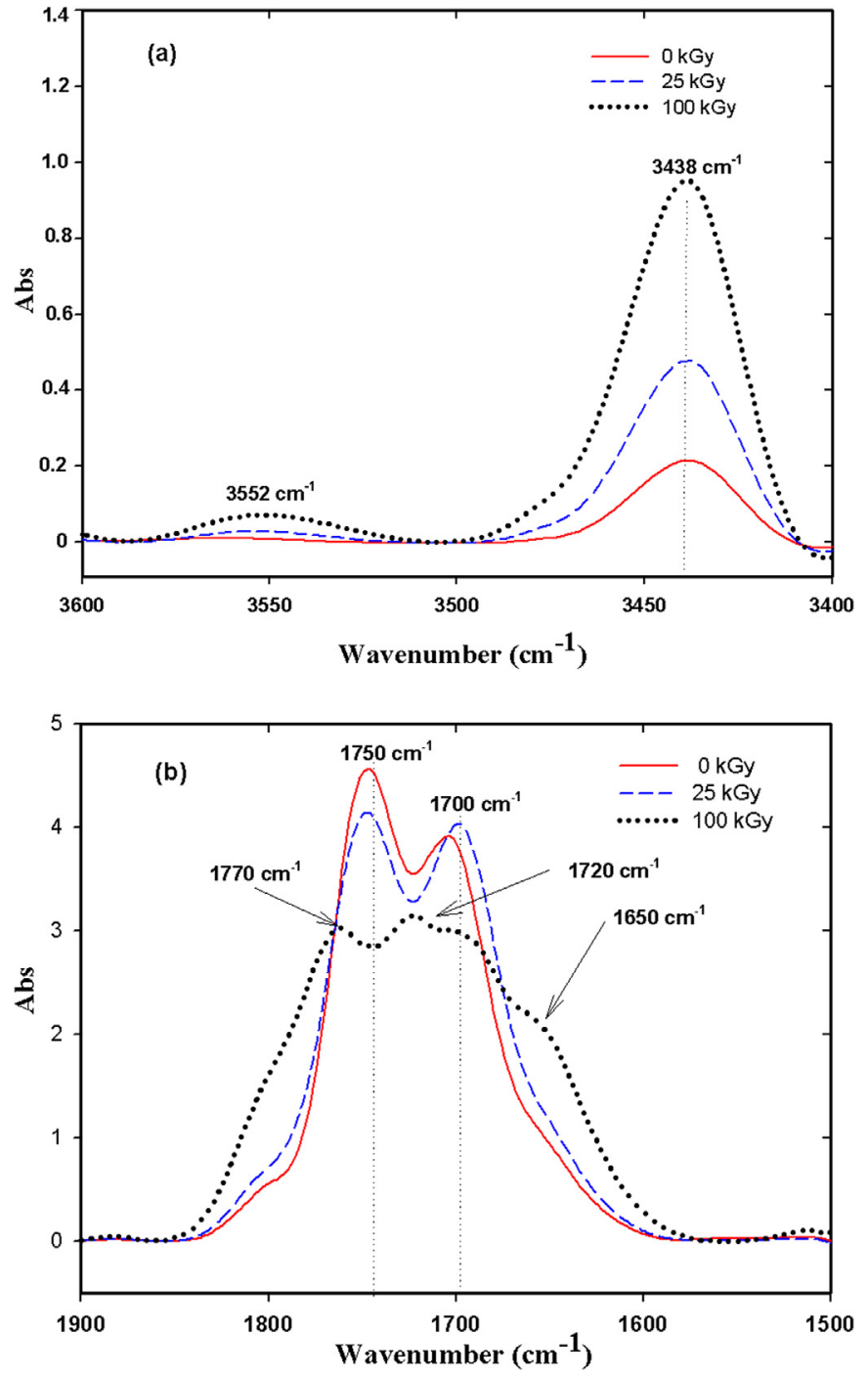

Fig. 1. FT-IR spectra of neat PHBV at various $\gamma$-radiation doses: (a) $3600-3400 \mathrm{~cm}^{-1}$ and (b) $1900-1500 \mathrm{~cm}^{-1}$.

\subsection{Molecular weight changes by SEC}

The values of $\bar{M}_{w}, \bar{M}_{n}$ and PDI determined by SEC analysis at 50 and $100 \mathrm{kGy}$ for neat PHBV, neat PLA and PHBV/PLA blends, with 

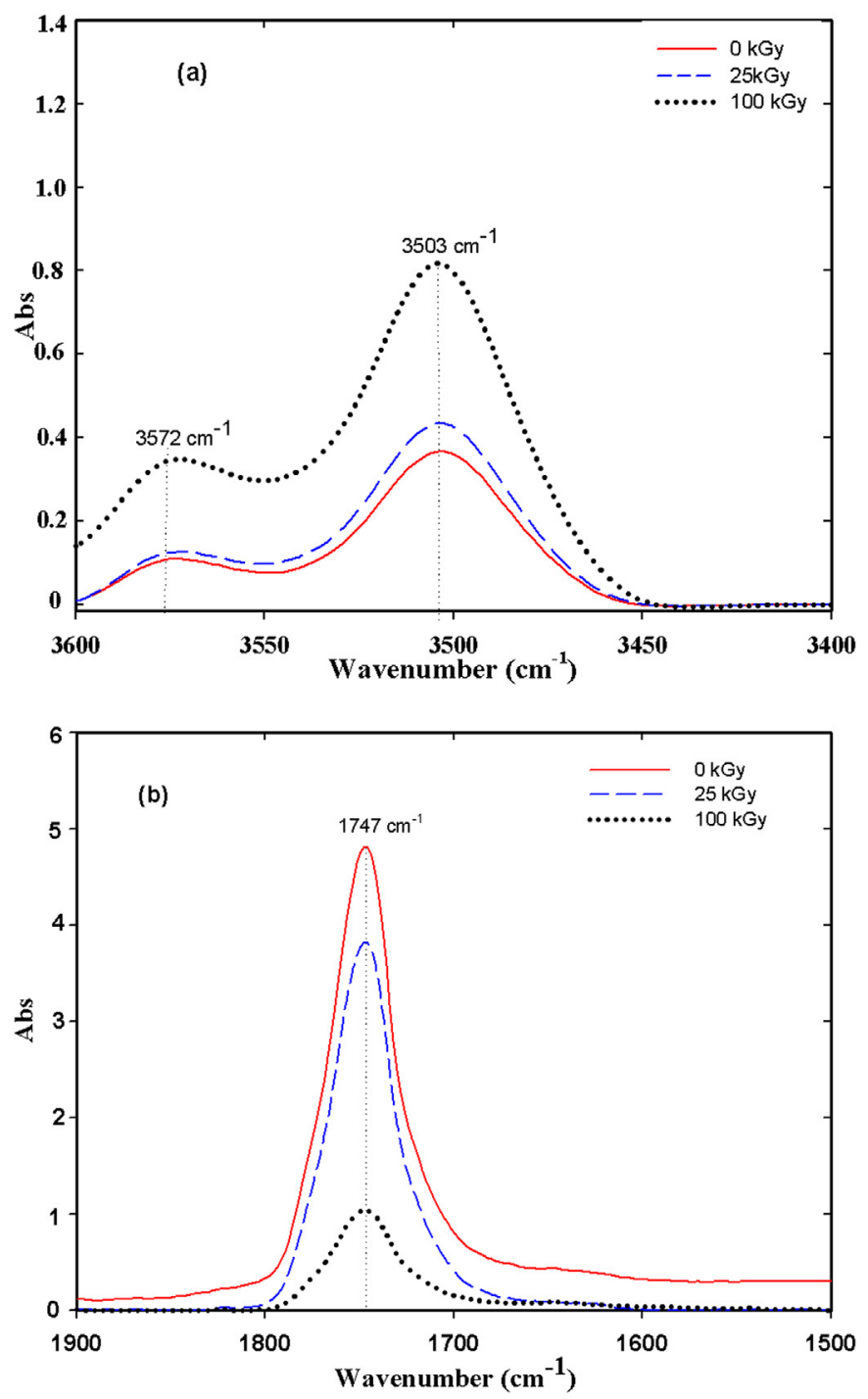

Fig. 2. FT-IR spectra of neat PLA at various $\gamma$-radiation doses: (a) $3600-3400 \mathrm{~cm}^{-1}$ and (b) $1900-1500 \mathrm{~cm}^{-1}$.

and without compatibilizer and $\mathrm{C} 30 \mathrm{~B}$, are reported in Table 1 . It is observed that the average molecular weight of the whole irradiated samples logically decreases with increase of absorbed dose due to degradation. Indeed, after 50 and $100 \mathrm{kGy}, \bar{M}_{w}$ of neat PHBV decreases by almost 55 and $73 \%$ compared to that of non-irradiated sample, respectively. Further, the significant decrease in both $\bar{M}_{w}$ and $\bar{M}_{n}$ of irradiated PHBV samples coupled with a slight increase in the PDI values is an indication of the dominance of chain scission mechanism. A similar trend is also observed for $\bar{M}_{w}$ and $\bar{M}_{n}$ of PLA, whose values shift toward smaller ones.

On the contrary, the results reported in Table 1 for PHBV/PLA blend indicate a quasi-stability of the average molecular weight up to the absorbed dose of $50 \mathrm{kGy}$. This may be explained as a result of some chemical interactions which probably occur between PHBV and PLA to form stronger bonds. In fact, it has been reported in the literature $[7,13,14]$ that, during $\gamma$-irradiation exposure of PHBV and PLA, different types of radicals are formed by chain scission, which may lead to some reactions such as transfer or chain recombination occurring separately or simultaneously in the two polymers. However, from 50 to $100 \mathrm{kGy}$, a significant reduction in both $\bar{M}_{w}$ and $\bar{M}_{n}$ is observed. Table 1 also indicates that the incorporation of C30B in PHBV/PLA blend slightly decreases $\bar{M}_{w}$ and $\bar{M}_{n}$ compared to
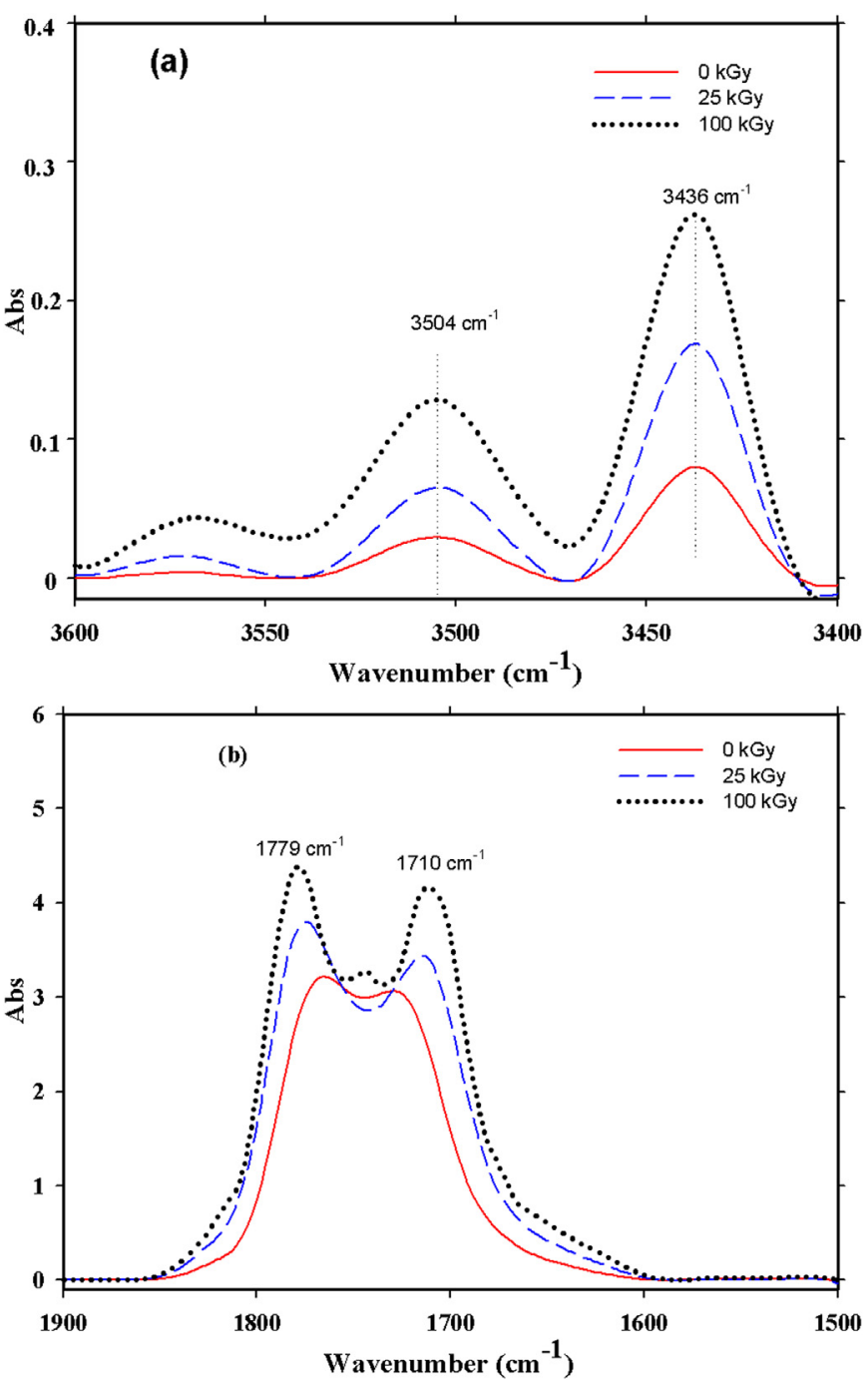

Fig. 3. FT-IR spectra of PHBV/PLA (50/50) blend at various $\gamma$-radiation doses: (a) $3600-3400 \mathrm{~cm}^{-1}$ and (b) $1900-1500 \mathrm{~cm}^{-1}$.

unfilled material, before $\gamma$-irradiation exposure. This is generally attributed to the effects of both shear mixing of PHBV/PLA blend and $\mathrm{C} 30 \mathrm{~B}$, resulting in hydrolysis of the two polymers, and also the relatively high processing temperature $\left(180{ }^{\circ} \mathrm{C}\right)$ [7]. At absorbed dose of $50 \mathrm{kGy}$, PHBV/PLA/C30B samples exhibit more than $60 \%$ decrease in both $\bar{M}_{w}$ and $\bar{M}_{n}$ compared to non-irradiated ones. This important decrease in molecular weight may be explained as a result of chain scission mechanism, which takes place in the amorphous regions of the two polymers. The addition of $5 \mathrm{wt} . \%$ of PHBV-g-MA to PHBV/PLA/C30B induces a large decrease $(\sim 40 \%)$ in both $\bar{M}_{w}$ and $\bar{M}_{n}$, due probably to the low molecular weight of the compatibilizer. However, at absorbed doses of 50 and $100 \mathrm{kGy}$, the decrease in both $\bar{M}_{w}$ and $\bar{M}_{n}$ of compatibilized PHBV/PLA/C30B is relatively smaller than the uncompatibilized samples. This counterbalancing effect of PHBV-g-MA compatibilizer may be the result of several factors, among them, the reduction of interfacial tension of the system due to increased interfacial interactions between the blend components, and also the localization of the clay in the blend due to the chemical linkage.

\subsection{Thermogravimetric analysis (TGA)}

The effects of gamma irradiation on the thermal stability of neat 

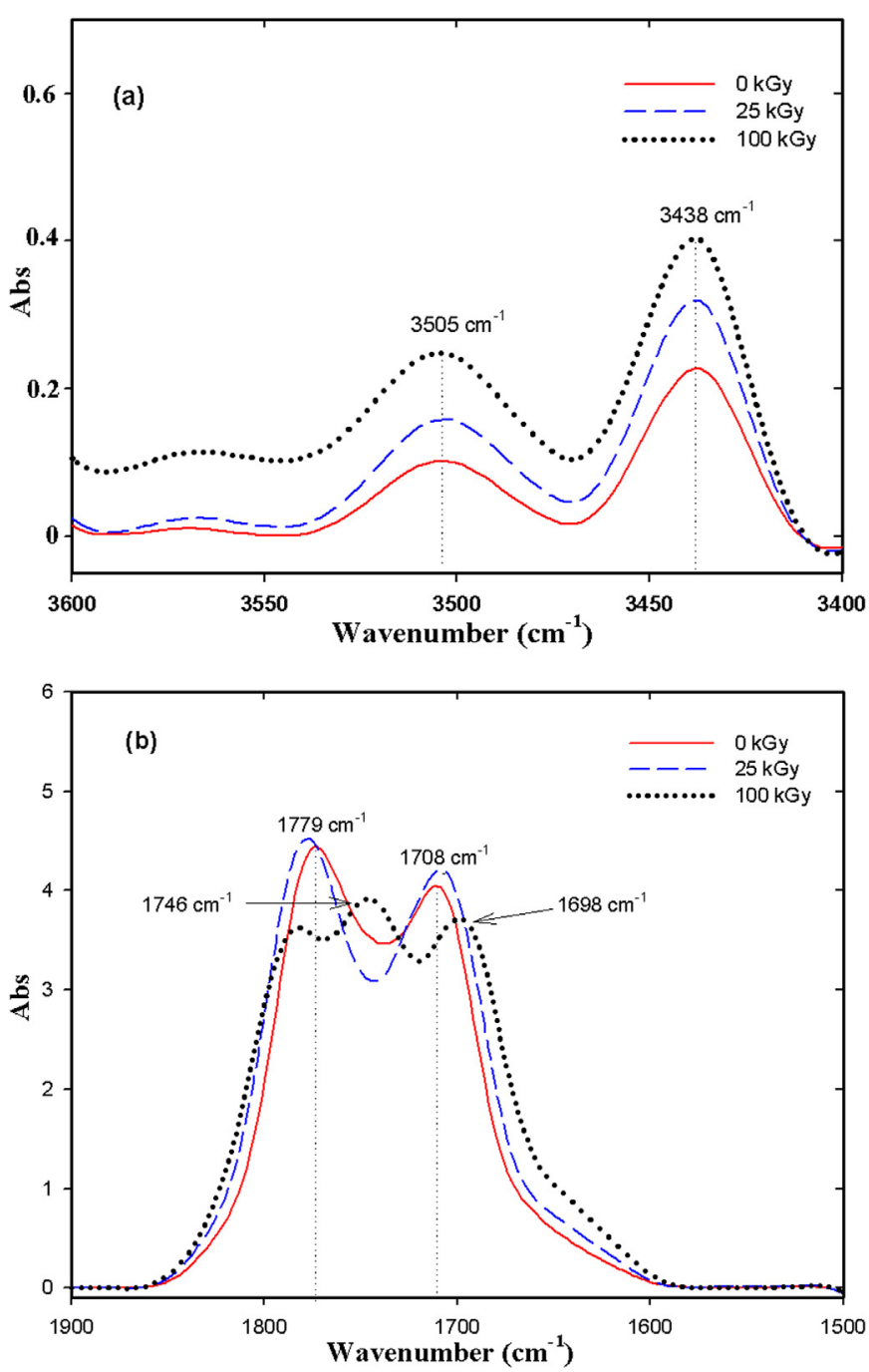

Fig. 4. FT-IR spectra of PHBV/PLA/PHBV-g-MA/C30B at various $\gamma$-radiation doses: (a) $3600-3400 \mathrm{~cm}^{-1}$ and (b) $1900-1500 \mathrm{~cm}^{-1}$.

PHBV, neat PLA and various PHBV/PLA blends in the presence of both $\mathrm{C} 30 \mathrm{~B}$ and PHBV-g-MA compatibilizer are shown in Table 2, where the degradation temperature values determined at $\mathrm{T}_{5 \%}, \mathrm{~T}_{10 \%}$, $\mathrm{T}_{50 \%}$ and the \% residue are given at $100 \mathrm{kGy}$.

From Table 2, it clearly appears that, up to $100 \mathrm{kGy}$, the effect of gamma irradiation is almost negligible for neat PHBV and PHBV/ PLA blends. Only, PLA was significantly affected since $\mathrm{T}_{5 \%}$ and $\mathrm{T}_{10 \%}$ were decreased by almost -21 and $-12{ }^{\circ} \mathrm{C}$, respectively, after $100 \mathrm{kGy}$.

On the other hand, the incorporation of C30B in PHBV/PLA blend leads to an increase in $\mathrm{T}_{5 \%}, \mathrm{~T}_{10 \%}$ and $\mathrm{T}_{50 \%}$ of the blend material by almost 10,9 and $8^{\circ} \mathrm{C}$, respectively. As expected, this result is due to the presence of inorganic layered silicates in PHBV/PLA blends, which restrict the diffusion of volatile degradation products throughout the nanocomposite materials, thus counterbalancing the degradation effect. The data given in Table 2 show clearly that the values of $\mathrm{T}_{5 \%}, \mathrm{~T}_{10 \%}$ and $\mathrm{T}_{50 \%}$ of PHBV/PLA/C30B corresponding to 286, 291 and $320^{\circ} \mathrm{C}$, respectively remain almost unchanged after absorbed dose of $100 \mathrm{kGy}$. This indicates the good thermal stability of PHBV/PLA/C30B compared to unfilled material. Moreover, the addition of PHBV-g-MA to PHBV/PLA/C30B has no noticeable effect on the thermal stability.

\subsection{Thermal analysis by DSC}

Further information about changes in the crystallinity as well as the thermal characteristics induced by $\gamma$-irradiation exposure of the samples was obtained by DSC. In this respect, Fig. 5 displays the DSC thermograms of neat polymers, i.e. PHBV and PLA, and also those of PHBV/PLA blends (50/50 w/w) before exposure and after $100 \mathrm{kGy}$. The values of thermal characteristics at absorbed dose of 25 and $100 \mathrm{kGy}$ are also shown in Table 3. Before $\gamma$-irradiation, DSC thermograms of neat PHBV and neat PLA display one single melting peak at approximately 171 and $150{ }^{\circ} \mathrm{C}$, respectively. As expected, DSC thermogram of PHBV/PLA blend shows the presence of two melting peaks at about 150 and $169{ }^{\circ} \mathrm{C}$, which correspond to those of neat polymers, i.e. PLA and PHBV, respectively. In addition, it can be also observed that all thermal characteristics, i.e. $T_{c}, T_{c c}, \Delta H_{c}$, $\Delta \mathrm{H}_{\mathrm{cc}}, \mathrm{T}_{\mathrm{m}}$ and $\Delta \mathrm{H}_{\mathrm{m}}$ of PHBV/PLA/C30B nanocomposites slightly shift to lower values by $\gamma$-irradiation exposure. This is attributed to a decrease in the arrangement of PHBV and PLA polymer chains due to the presence of $\mathrm{C} 30 \mathrm{~B}$ in the blend material [7].

After $100 \mathrm{kGy}$, the DSC thermograms of all irradiated samples exhibit double peak endotherms when compared to the non irradiated ones having a single peak. According to the literature [18], the formation of a secondary melting peak could be the result of the polymer chains re-organization during $\gamma$-irradiation and also the occurrence of different crystal populations with different lamellar thickness. Furthermore, for all irradiated samples the melting peaks shift to lower temperatures and become broader with increased absorbed dose. The decrease in $\mathrm{T}_{\mathrm{m}}$ with absorbed dose is attributed to the formation of polymer chains with lower molecular weight. Besides this, $\mathrm{T}_{\mathrm{c}}$ shifts to lower temperatures, while $\Delta \mathrm{H}_{\mathrm{c}}$ slightly decreases with increasing the radiation dose. $\mathrm{T}_{\mathrm{cc}}$ becomes much sharper and shifts to a lower temperature, indicating a higher crystallization rate in the irradiated samples resulting from chain segments formation. The lower molecular weight resulting from the chain scission is a precondition for the increase of the mobility of macromolecules which reinforces their potential for reorganization and crystallization at a lower temperature [26-28].

Table 2

Values of degradation temperature at $\mathrm{T}_{5 \%}, \mathrm{~T}_{10 \%}, \mathrm{~T}_{50 \%}$ and char yield at $600{ }^{\circ} \mathrm{C}$ of neat PHBV, neat PLA and various PHBV/PLA blend samples before and after $100 \mathrm{kGy}$ of irradiation determined by TGA.

\begin{tabular}{|c|c|c|c|c|c|}
\hline Samples & Absorbed dose (kGy) & $\mathrm{T}_{5 \%}\left({ }^{\circ} \mathrm{C}\right)$ & $\mathrm{T}_{10 \%}\left({ }^{\circ} \mathrm{C}\right)$ & $\mathrm{T}_{50 \%}\left({ }^{\circ} \mathrm{C}\right)$ & Char yield (\%) \\
\hline PHBV & 0 & 267 & 273 & 286 & 1.3 \\
\hline PLA & 0 & 332 & 341 & 362 & 0.2 \\
\hline PHBV/PLA & 100 & 271 & 272 & 301 & 0.5 \\
\hline \multirow[t]{2}{*}{ PHBV/PLA/C30B } & 0 & 286 & 291 & 320 & 2.7 \\
\hline & 100 & 284 & 289 & 317 & 2.6 \\
\hline
\end{tabular}



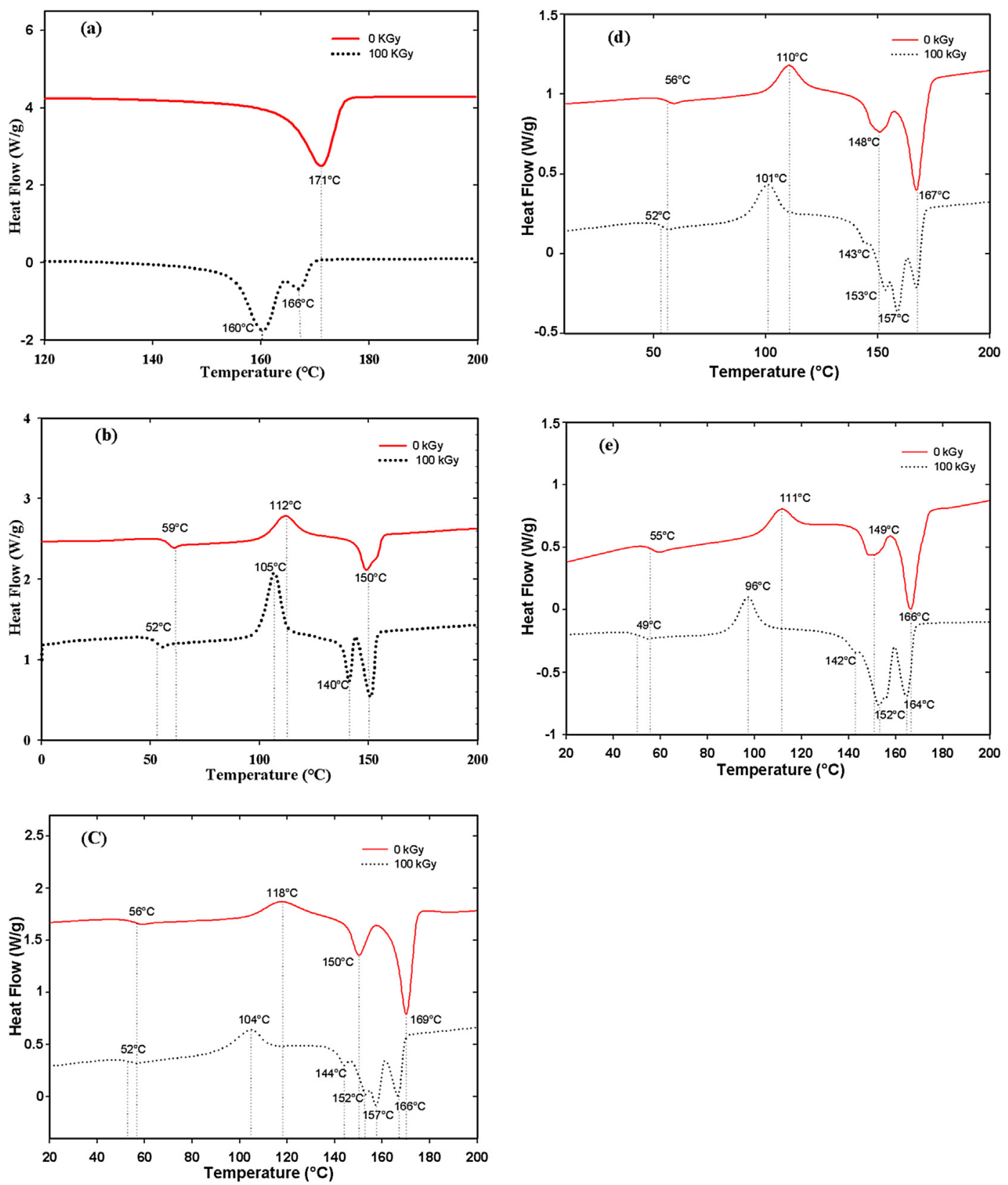

Fig. 5. DSC thermograms of neat PHBV (a), neat PLA (b), PHBV/PLA blend (c), PHBV/PLA/C30B (d) and PHBV/PLA/PHBV-g-MA/C30B (e), before and after 100 kGy of irradiation.

Table 3

Thermal characteristics for neat PHBV, neat PLA and various PHBV/PLA blends before and after absorbed doses of 25 and 100 kGy determined by DSC.

\begin{tabular}{|c|c|c|c|c|c|c|c|}
\hline Samples & Doses (kGy) & $\mathrm{T}_{\mathrm{C}, \mathrm{PHBV}}\left({ }^{\circ} \mathrm{C}\right)$ & $\Delta \mathrm{H}_{\mathrm{c}, \operatorname{PHBV}}(\mathrm{J} / \mathrm{g})$ & $\mathrm{T}_{\mathrm{cc}, \mathrm{PLA}}\left({ }^{\circ} \mathrm{C}\right)$ & $\Delta \mathrm{H}_{\mathrm{cC}, \mathrm{PLA}}(\mathrm{J} / \mathrm{g})$ & $\mathrm{T}_{\mathrm{m}}\left({ }^{\circ} \mathrm{C}\right)$ & $\Delta \mathrm{H}_{\mathrm{m}}(\mathrm{J} / \mathrm{g})$ \\
\hline \multirow[t]{2}{*}{ PHBV } & 0 & 118 & 92 & - & - & 171 & 103 \\
\hline & 100 & 114 & 104 & - & - & $160-166$ & 115 \\
\hline \multirow[t]{2}{*}{ PLA } & 0 & - & - & 112 & 24 & 150 & 24 \\
\hline & 100 & - & - & 107 & 41 & $140-150$ & 46 \\
\hline \multirow[t]{2}{*}{ PHBV/PLA } & 0 & 118 & 47 & 118 & 16 & $150-169$ & 64 \\
\hline & 25 & 116 & 44 & 110 & 17 & $147-155-165$ & 67 \\
\hline PHBV/PLA/C30B & 100 & 112 & 44 & 101 & 18 & $143-153-157-167$ & 70 \\
\hline \multirow[t]{3}{*}{ PHBV/PLA/OMMT/PHBV-g-MA } & 0 & 115 & 38 & 112 & 15 & $149-166$ & 56 \\
\hline & 25 & 115 & 43 & 108 & 17 & $147-155-165$ & 68 \\
\hline & 100 & 112 & 48 & 97 & 19 & $142-152-155-164$ & 71 \\
\hline
\end{tabular}




\subsection{Morphological analysis by SEM}

Fig. 6(a) and (b) show SEM micrographs of the fracture surface of neat PHBV before and after absorbed dose of $50 \mathrm{kGy}$, respectively, at a magnification of 2000. In Fig. 6(a), before gamma irradiation exposure, the morphology of neat PHBV shows an irregular fracture surface due to its crystalline structure. However, at absorbed dose of $50 \mathrm{kGy}$, the fracture surface of neat PHBV in Fig. 6(b), exhibits some irregularities and defects as a result of degradation. In Fig. 6(c), corresponding to non-irradiated PLA, it is observed that the sample displays no significant defects on the fracture surface. After $50 \mathrm{kGy}$ (Fig. 6(d)), the fracture surface of irradiated PLA sample exhibits a few irregularities exhibiting less damage compared to that of neat PHBV. For PHBV/PLA blends shown in Fig. 6(e), the SEM micrograph exhibits separated phase morphology between PHBV and PLA with poor adhesion at interfaces [19]. The separated phase morphology indicates immiscibility between the two biopolymers. Indeed, PLA domains appear as beads in PHBV matrix, whose size and distribution are very irregular. At absorbed dose of $50 \mathrm{kGy}$, the fracture surface of PHBV/PLA blend illustrated in Fig. 6(f) shows an homogeneous distribution of PLA in PHBV matrix with a reduction in domain size of PLA. This result is interesting since it clearly indicates that $\gamma$-irradiation may promote and enhance the compatibility between PHBV and PLA. This enhancement in the compatibility between the two components of the blend without any compatibilizer may be induced by the chemical modifications due to the degradation and previously highlighted using FT-IR.

Fig. 6(g) shows the fracture surface of PHBV/PLA blend reinforced with 3 wt.\% of C30B in the presence of PHBV-g-MA compatibilizer before $\gamma$-irradiation. The SEM micrograph shows that the addition of PHBV-g-MA and C30B improves the interfacial (a)

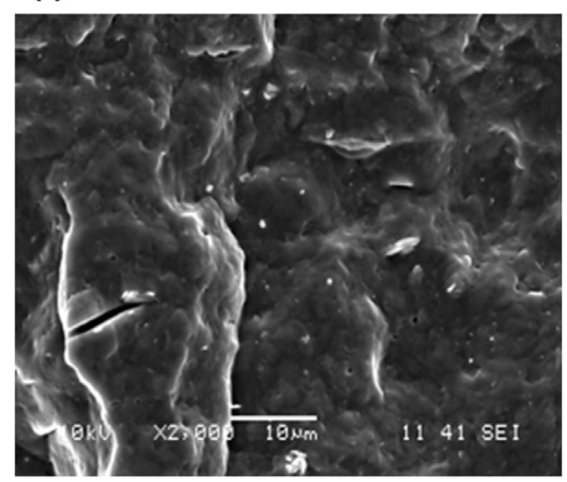

(b)

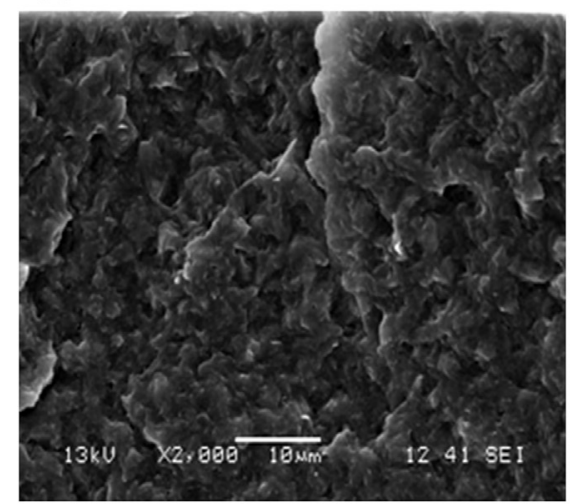

(c)

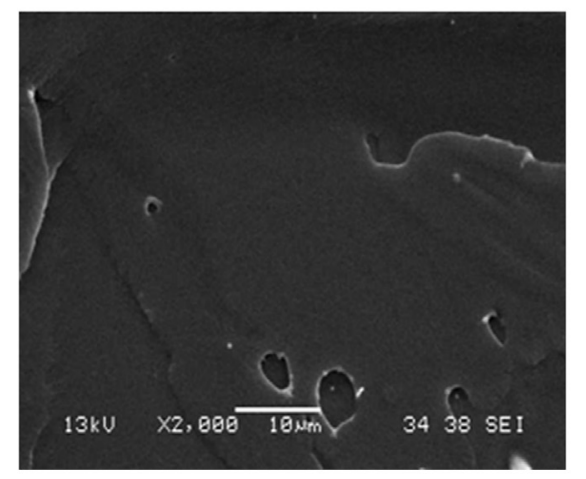

(d)

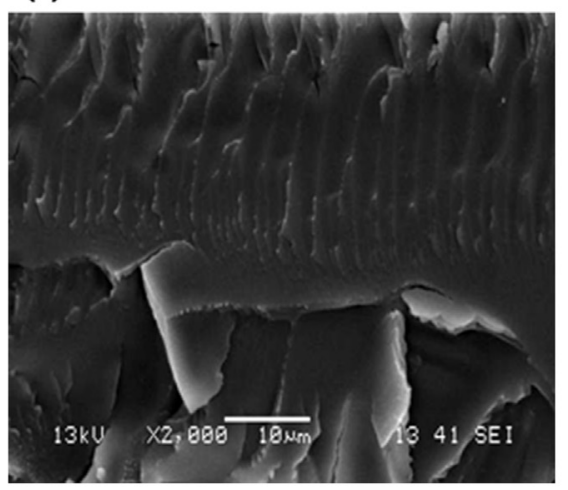

(e)

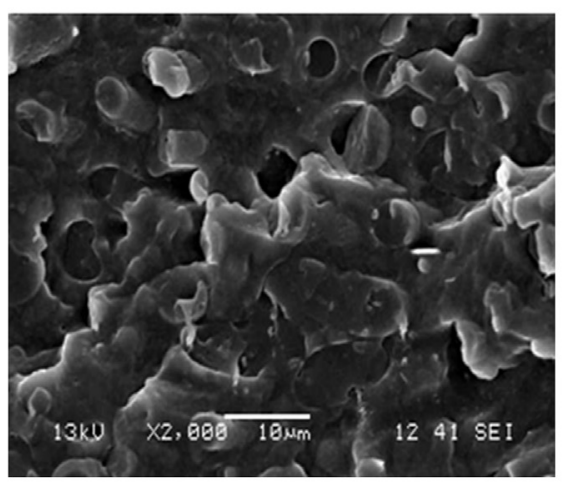

(f)

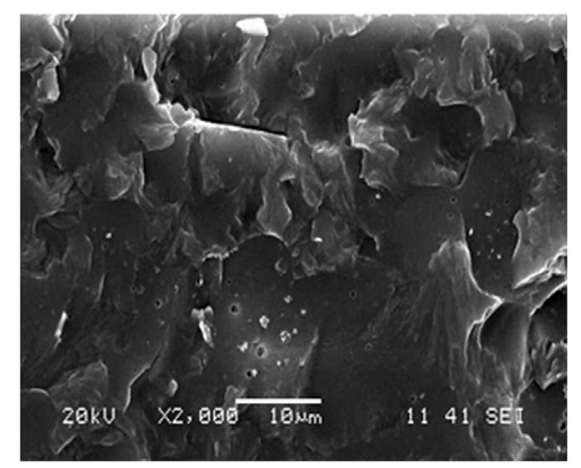

(g)

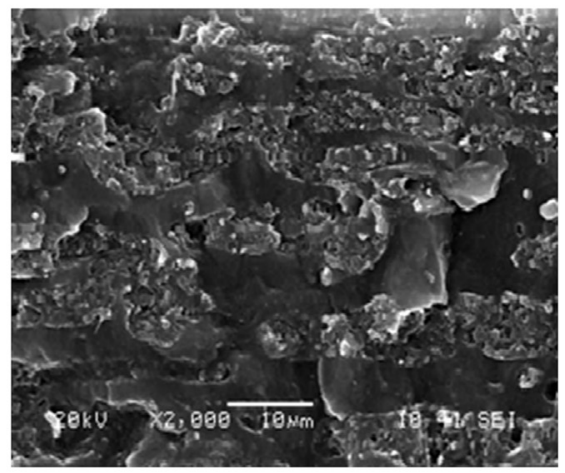

(h)

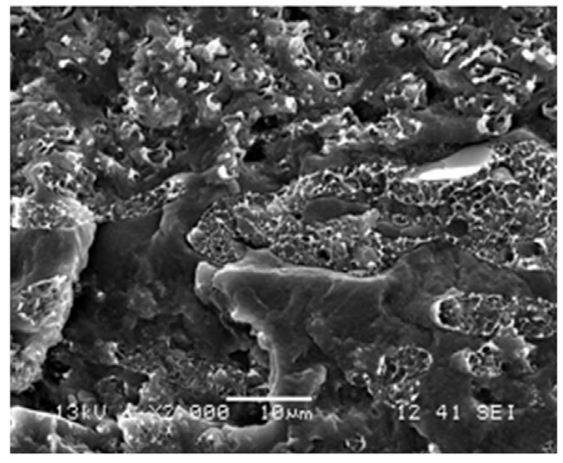

Fig. 6. SEM micrographs of fractured surface of: PHBV (a): 0 kGy and (b): 50 kGy; PLA (c): 0 kGy and (d): 50 kGy; PHBV/PLA blend (e): 0 kGy and (f): 50 kGy; PHBV/PLA/PHBV-g-MA/ C30B (g): $0 \mathrm{kGy}$ and (h): $50 \mathrm{kGy}$. 
adhesion and the miscibility between PHBV and PLA. After absorbed dose of $50 \mathrm{kGy}$, the fracture surface of the irradiated sample shown in Fig. 6(h), remains almost the same as the non-irradiated one, despite the presence of a few surface irregularities, which may be probably attributed to an increase in the crystallinity of the irradiated sample.

\subsection{Nanoindentation measurements}

Table 4 reports the values of nanoindentation modulus and hardness measured for neat PHBV, neat PLA and PHBV/PLA blends in the presence of both C30B and PHBV-g-MA compatibilizer before and after the absorbed dose of $100 \mathrm{kGy}$. The values are averaged for indentation depths of $1200-1500 \mathrm{~nm}$ from a minimum of 64 indents. A Poisson's ratio of 0.35 was used in all modulus calculations [29].

The data provided in Table 4 indicate a very large decrease in both nanoindentation modulus and hardness for neat PHBV and neat PLA after $100 \mathrm{kGy}$. Indeed, the value of nanoindentation modulus of PHBV and PLA decreases by almost 67 and $45 \%$, respectively, after $100 \mathrm{kGy}$. This may be explained as being a result of the significant reduction in both $\bar{M}_{w}$ and $\bar{M}_{n}$ due to chain scission mechanism. This is in agreement with the literature data [30].

For unexposed PHBV/PLA blends, the expected nanoindentation modulus and hardness, being intermediate between PHBV and PLA could be noted; moreover, a slight increase of the mechanical properties is logically highlighted for the C30B loaded blends. Interestingly, for PHBV/PLA blends, no significant change in the values of modulus and hardness was observed after the absorbed dose of $100 \mathrm{kGy}$ compared with the non-irradiated samples. Indeed, only $8 \%$ decrease is obtained in the modulus of PHBV/PLA blend after $100 \mathrm{kGy}$, while the hardness decreases by almost 11\% compared to the non-irradiated sample. Furthermore, one can observe that the values of modulus and hardness remain almost unchanged for all PHBV/PLA blends and seem to be not affected by the presence of either $\mathrm{C} 30 \mathrm{~B}$ or PHBV-g-MA compatibilizer. This indicates that local mechanical properties of PHBV/PLA blends are stable to $\gamma$-irradiation exposure up to $100 \mathrm{kGy}$, evidencing a morphological effect. In this case, the decrease into the molecular weight, being penalizing for the nanoindentation properties, is positively counter-balanced by both the PHBV/PLA compatibility and crystallinity increase after the irradiation exposure.

\subsection{Flammability properties by PCFC}

The pyrolysis combustion flow calorimeter (PCFC) is a relevant tool for assessing the flammability of fire retardant polymers at a microscopic scale [31]. PCFC experiments were performed in order to evaluate the fire retardant mechanism of filled blends versus unfilled ones and irradiated films versus non-irradiated ones. As observed for TGA data in Table 2, the temperature of the peak of
Heat Release Rate (TpHRR) is lower for PHBV in comparison with that of PLA. PHBV releases a higher amount of heat (THR) in comparison with PLA. For the blends, an intermediate value of THR is obtained. Moreover, it can be noted that PCFC plots of all PHBV/PLA blends exhibit two HRR peaks corresponding, respectively, to the degradation of each polymer. For the unfilled blend, TpHRR of PHBV is increased while TPHRR of PLA is decreased, which tends to suggest the formation of copolymers during the mixing stage or during the pyrolysis.

The incorporation of $\mathrm{C} 30 \mathrm{~B}$ tends to improve mainly the fire behavior of PHBV since only TPHRR of PHBV is increased. Nevertheless, a decrease of the two pHRR peaks and THR is seen which shows the effect of the organomodified clay. These effects are more pronounced in the presence of PHBV-g-MA which allows better dispersion of $\mathrm{C} 30 \mathrm{~B}$ to delay the emission of volatile combustibles.

The influence of irradiation on the parameters of pure polymers seems only significant for the PHRR of PLA, which is lowered.

In the unfilled blend, TpHRR does not vary clearly as a function of the absorbed dose. Conversely, pHRR values for each polymer present contrasted evolutions when the dose increases. pHRR for PHBV tends to increase, suggesting the formation of new macromolecular structures from both polymers due to irradiation. Also, at the maximum dose of $100 \mathrm{kGy}$, the THR value seems close to that of pure PHBV. All these results tend to indicate that the new macromolecular structures formed behave like PHBV and lower the fire reaction of the blend.

Fortunately, the incorporation of $\mathrm{C} 30 \mathrm{~B}$ alone or in combination with the compatibilizer seems to create a barrier effect to the volatile combustible release through better dispersion of silicate sheets and strong interfacial adhesion. From Table 1, it appears that the influence of radiations on chain scission is reduced due to the silicate dispersion, so the nanostructure can be maintained at higher temperature. Whatever the level of irradiation, the two pHRR are reduced in comparison with these of unfilled and nonirradiated blend. Moreover, the THR values at $100 \mathrm{kGy}$ for the filled blends (with and without PHBV-g-MA) are similar as those of the unfilled and non-irradiated blend. Consequently, good compatibilization owing to the presence of the organomodified clay can compensate the effect of irradiation on fire retardancy of PHBV/PLA blends (Table 5) (Fig. 3).

\section{Conclusions}

From this study, it can be concluded that the effects of $\gamma$-irradiation on PHBV/PLA: 50/50 w/w blends resulted in strong modifications in the chemical structure, especially after $100 \mathrm{kGy}$ of absorbed dose. Indeed, carbonyl products were formed during degradation, which was responsible for the decrease in the average molecular weight of all irradiated samples due to the chain scission mechanism, being much more pronounced for the neat polymers, i.e. PHBV and PLA. However, thermal stability as well as modulus

Table 4

Values of modulus and hardness of PHBV, PLA and various PHBV/PLA blends before and after 100 kGy of irradiation measured by nanoindentation.

\begin{tabular}{|c|c|c|c|}
\hline Samples & Absorbed dose (kGy) & Modulus (GPa) & Hardness (GPa) \\
\hline \multirow[t]{2}{*}{ PHBV } & 0 & $6.3 \pm 0.5$ & $0.22 \pm 0.02$ \\
\hline & 100 & $2.1 \pm 0.8$ & $0.05 \pm 0.01$ \\
\hline \multirow[t]{2}{*}{ PLA } & 0 & $4.3 \pm 1.1$ & $0.11 \pm 0.03$ \\
\hline & 100 & $2.4 \pm 0.9$ & $0.08 \pm 0.05$ \\
\hline \multirow[t]{2}{*}{ PHBV/PLA } & 0 & $5.3 \pm 0.4$ & $0.23 \pm 0.03$ \\
\hline & 100 & $5.1 \pm 0.5$ & $0.21 \pm 0.02$ \\
\hline \multirow[t]{2}{*}{ PHBV/PLA/C30B } & 0 & $5.5 \pm 0.7$ & $0.21 \pm 0.04$ \\
\hline & 100 & $5.9 \pm 0.8$ & $0.24 \pm 0.04$ \\
\hline \multirow[t]{2}{*}{ PHBV/PLA/C30B/PHBV-g-MA } & 0 & $5.5 \pm 0.9$ & $0.20 \pm 0.04$ \\
\hline & 100 & $5.6 \pm 0.5$ & $0.19 \pm 0.03$ \\
\hline
\end{tabular}


Table 5

TpHRR, pHRR and THR from PCFC tests of neat PLA, PHBV/PLA blend and PHBV/PLA/C30B/PHBV-g-MA before and after $\gamma$-irradiation.

\begin{tabular}{|c|c|c|c|c|}
\hline Samples & Absorbed dose (kGy) & $\operatorname{TpHRR}\left({ }^{\circ} \mathrm{C}\right)$ & pHRR (W/g) & THR $(\mathrm{KJ} / \mathrm{g})$ \\
\hline \multirow[t]{4}{*}{ PHBV } & 0 & $293.3 \pm 6.4$ & $963 \pm 077$ & $20.0 \pm 0.2$ \\
\hline & 25 & $291.5 \pm 0.7$ & $996 \pm 022$ & $19.2 \pm 0.1$ \\
\hline & 50 & $295.0 \pm 5.6$ & $896 \pm 102$ & $19.9 \pm 0.6$ \\
\hline & 100 & $293.7 \pm 6.7$ & $949 \pm 138$ & $20.2 \pm 0.9$ \\
\hline \multirow[t]{4}{*}{ PLA } & 0 & $370.5 \pm 2.1$ & $494.5 \pm 62$ & $15.0 \pm 0.2$ \\
\hline & 25 & $373.5 \pm 6.4$ & $431.5 \pm 13$ & $14.6 \pm 0.1$ \\
\hline & 50 & $374.5 \pm 3.5$ & $428.5 \pm 10$ & $14.8 \pm 0.1$ \\
\hline & 100 & $372.0 \pm 4.2$ & $433.5 \pm 05$ & $16.4 \pm 0.3$ \\
\hline \multirow[t]{4}{*}{ PHBV/PLA } & 0 & 299/375 & $208 / 436$ & $17.5 \pm 0.4$ \\
\hline & 25 & $298 / 372$ & $202 / 431$ & $17.2 \pm 0.6$ \\
\hline & 50 & $297 / 370$ & $187 / 430$ & $16.8 \pm 0.6$ \\
\hline & 100 & $295 / 367$ & $130 / 320$ & $19.0 \pm 0.6$ \\
\hline \multirow[t]{4}{*}{ PHBV/PLA/C30B } & 0 & $307 / 374$ & $195 / 372$ & $16.5 \pm 0.4$ \\
\hline & 25 & $306 / 369$ & $183 / 367$ & $16.4 \pm 0.4$ \\
\hline & 50 & $309 / 376$ & $171 / 350$ & $18.3 \pm 0.9$ \\
\hline & 100 & $310 / 375$ & $169 / 346$ & $17.8 \pm 0.1$ \\
\hline \multirow[t]{4}{*}{ PHBV/PLA/C30B/PHBV-g-MA } & 0 & $306 / 367$ & $201 / 344$ & $16.1 \pm 0.9$ \\
\hline & 25 & $309 / 376$ & $188 / 345$ & $16.5 \pm 0.5$ \\
\hline & 50 & $309 / 374$ & $170 / 371$ & $16.0 \pm 0.3$ \\
\hline & 100 & $305 / 371$ & $177 / 355$ & $17.0 \pm 0.1$ \\
\hline
\end{tabular}

and hardness of PHBV/PLA blends remained almost unchanged during $\gamma$-irradiation test, and enhancement of these properties was observed in the presence of C30B and PHBV-g-MA. Indeed, SEM data confirm the morphological stability of PHBV/PLA/C30B/PHBVg-MA after $50 \mathrm{kGy}$ compared to non-irradiated material. These results clearly demonstrate that, up to $100 \mathrm{kGy}$, such blend materials are stable and may have some potential applications considering that the regular doses for food irradiation are lower than $10 \mathrm{kGy}$, and for packaging sterilization the doses are lower than 25 kGy.

\section{Acknowledgments}

The authors would like to thank the International Atomic Energy Agency through the Research Contract $n^{\circ} 17692 / R 1$ and they are also grateful to EGIDE through the TASSILI program 12 MDU 871 for its financial support in this collaborative project. The authors are pleased to express their grateful acknowledgments to Dr. Jean-Luc Audic, Dr. Isabelle Pillin, Antoine Kervoelen, Anthony Magueresse and Françoise Peresse for their help in the experimental work.

\section{References}

[1] E. Bugnicourt, P. Cinelli, A. Lazzeri, V. Alvarez, Exp. Polym. Lett. 8 (2014) 791.

[2] H.S. Kim, H.S. Yang, H.J. Kim, B.J. Lee, T.S. Hwang, J. Therm. Anal. Calorim. 81 (2005) 299.

[3] J. Vandewijngaarden, M. Murariu, P. Dubois, R. Carleer, J. Yperman, P. Adriaensens, S. Schreurs, N. Lepot, R. Peeters, M. Buntinx, J. Polym. Env. 22 (2014) 501.

[4] E. Hermida, V.I. Mega, O. Yashchuk, V. Fernadez, P. Eisenberg, S.S. Miyazaki, Macromol. Symp. 263 (2008) 102

[5] A. Babanalbandi, D.J.T. Hill, A.K. Whittaker, Polym. Degrad. Stab. 58 (1997 203.

[6] J. Joswiakowska, R.A. Wach, B. Rokita, P. Ulanski, S.P. Nalawade, D.W. Grijpma, J. Feijen, J.M. Rosiak, Polym. Degrad. Stab. 96 (2011) 2541.
[7] L. Zaidi, S. Bruzaud, M. Kaci, A. Bourmaud, N. Gautier, Y. Grohens, Polym. Degrad. Stab. 98 (2013) 348.

[8] S. Dadbin, F. Naimian, Polym. Int. 63 (2014) 1063.

[9] E.C.L. Cardoso, S.R. Scagliusi, L.P. Lima, N.R. Bueno, A.J.C. Brant, D.F. Parra, A.B. Lugão, Radiat. Phys. Chem. 94 (2014) 249.

[10] N. García-Huete, J.M. Laza, J.M. Cuevas, J.L. Vilas, E. Bilbao, L.M. León, Radiat. Phys. Chem. 102 (2014) 108.

[11] H.M. Said, J. Radiat, Res. Appl. Sci. 6 (2013) 11.

[12] A. Buttafava, G. Consolati, M. Mariani, F. Quasso, U. Ravasio, Polym. Degrad. Stab. 89 (2005) 133.

[13] P. Nugroho, H. Mitomo, F. Yoshii, T. Kume, Polym. Degrad. Stab. 72 (2001) 337.

[14] F. Rosario, E. Corradini, S.A. Casarin, J.A.M. Agnelli, J. Polym. Environ. 21 (2013) 789.

[15] E.B. Hermida, V.I. Mega, O. Yashchuk, V. Fernandez, P. Eisenberg, S.S. Miyazaki, Macromol. Symp. 263 (2008) 102.

[16] L.M. Oliveira, P.L.B. Araujob, E.S. Araujob, Mater. Res. 16 (2013) 195.

[17] T. Yovcheva, M. Marudova, A. Viraneva, E. Gencheva, N. Balabanov, G. Mekishev, J. Appl. Polym. Sci. 128 (2013) 139.

[18] A. Bergmann, J. Tebmar, A. Owen, J. Mater. Sci. 42 (2007) 3732.

[19] I. Zembouai, M. Kaci, S. Bruzaud, A. Benhamida, Y.M. Corre, Y. Grohens, Polym. Test. 32 (2013) 842.

[20] I. Zembouai, S. Bruzaud, M. Kaci, A. Benhamida, Y.M. Corre, Y. Grohens, A. Taguet, J.M. Lopez-Cuesta, J. Polym. Environ. 22 (2014) 449.

[21] I. Zembouai, S. Bruzaud, M. Kaci, A. Benhamida, Y.M. Corre, Y. Grohens, J.M. Lopez-Cuesta, Polym. Eng. Sci. 54 (2014) 2239.

[22] I. Zembouai, S. Bruzaud, M. Kaci, A. Benhamida, Y.M. Corre, Y. Grohens, J. Polym. Environ. 22 (2014) 131.

[23] Y.M. Corre, S. Bruzaud, J.-L. Audic, Y. Grohens, Polym. Test. 31 (2012) 226.

[24] L. Zaidi, S. Bruzaud, A. Bourmaud, P. Médéric, M. Kaci, Y. Grohens, J. Appl. Polym. Sci. 116 (2010) 1357.

[25] Q.S. Liu, M.F. Zhu, W.H. Wu, Z.Y. Qin, Polym. Degrad. Stab. 94 (2009) 18.

[26] F. Rosario, E. Corradini, S.A. Casarin, J.A.M. Agnelli, J. Polym. Environ. 21 (2013) 789.

[27] D.F. Parra, D.S. Rosa, J. Rezende, P. Ponce, A.B. Lugao, J. Polym. Environ. 19 (2011) 918.

[28] L.M. Oliveira, E.S. Araujo, S.M.L. Guedes, Polym. Degrad. Stab. 91 (2006) 2157.

[29] S. Bruzaud, A. Bourmaud, Polym. Test. 26 (2007) 652

[30] M. Liu, Y. Yin, Z. Fan, X. Zheng, S. Shen, P. Deng, Nucl. Instr. Meth. Phys. Res. B 274 (2012) 139.

[31] R.E. Lyon, R.N. Walters, J. Anal. Appl. Pyr. 71 (2004) 27. 